
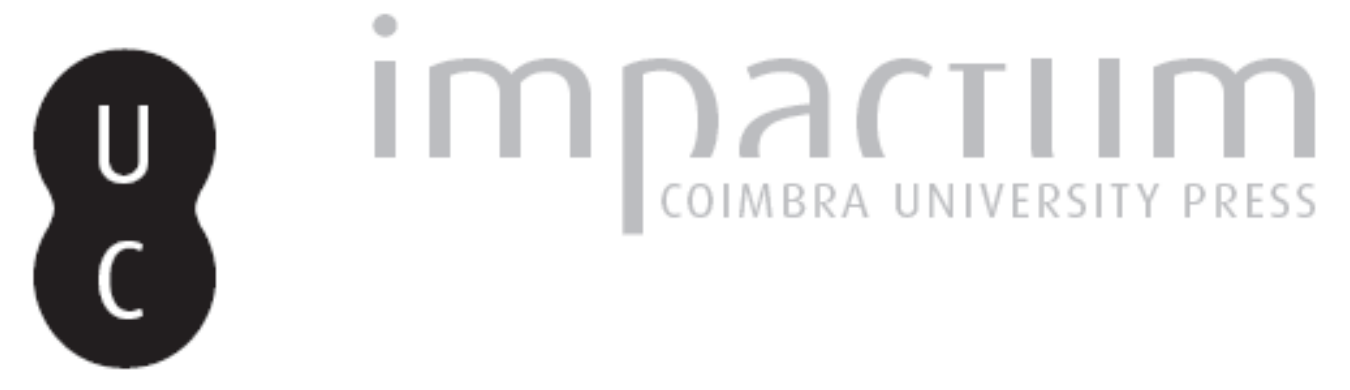

\title{
A reforma pombalina e as ciências auxiliares da História
}

\section{Autor(es): Cruz, António}

Publicado por: Imprensa da Universidade de Coimbra

URL persistente:

URI:http://hdl.handle.net/10316.2/43908

DOI:

DOI:https://doi.org/10.14195/2183-8925_4-2_5

Accessed : $\quad$ 26-Apr-2023 13:45:18

A navegação consulta e descarregamento dos títulos inseridos nas Bibliotecas Digitais UC Digitalis, UC Pombalina e UC Impactum, pressupõem a aceitação plena e sem reservas dos Termos e Condições de Uso destas Bibliotecas Digitais, disponíveis em https://digitalis.uc.pt/pt-pt/termos.

Conforme exposto nos referidos Termos e Condições de Uso, o descarregamento de títulos de acesso restrito requer uma licença válida de autorização devendo o utilizador aceder ao(s) documento(s) a partir de um endereço de IP da instituição detentora da supramencionada licença.

Ao utilizador é apenas permitido o descarregamento para uso pessoal, pelo que o emprego do(s) título(s) descarregado(s) para outro fim, designadamente comercial, carece de autorização do respetivo autor ou editor da obra.

Na medida em que todas as obras da UC Digitalis se encontram protegidas pelo Código do Direito de Autor e Direitos Conexos e demais legislação aplicável, toda a cópia, parcial ou total, deste documento, nos casos em que é legalmente admitida, deverá conter ou fazer-se acompanhar por este aviso.

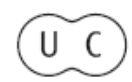




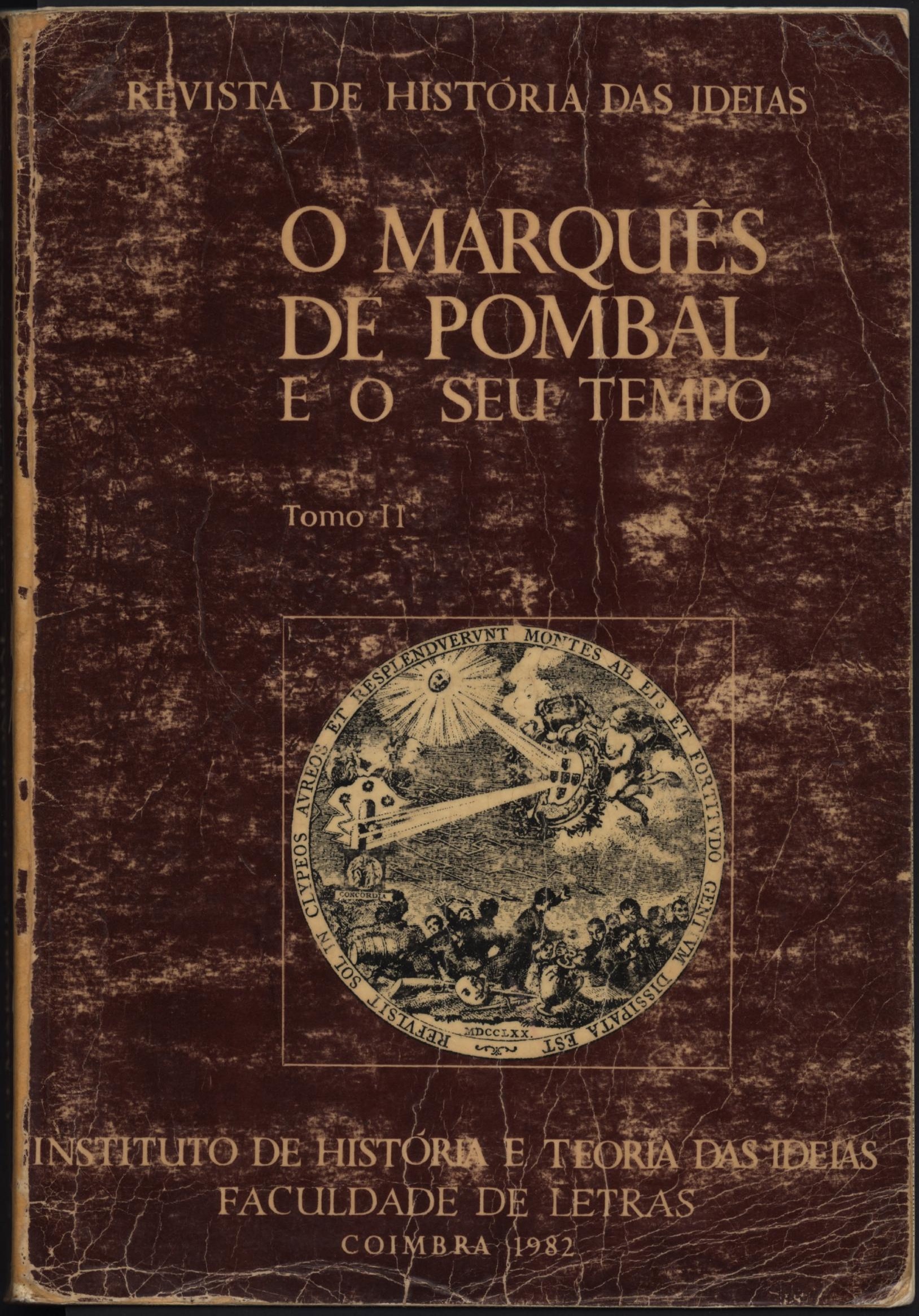




\section{A REFORMA POMBALINA E AS CIENCIAS AUXILIARES DA HISTÓRIA}

O reitor da Universidade de Coimbra Gaspar Saldanha de Albuquerque, que foi investido na prelazia académica a 29 de Dezembro de 1757, aguardava, decorrido pouco mais de um ano, que baixasse da Corte qualquer determinação régia proibindo as comunicações com os padres da Companhia de Jesus, à semelhança do que acontecera em Lisboa no mês de Janeiro de 1759. Tratou então de empreender diligências atinentes a evitar, quando tal se verificasse, prejuízos de maior para os escolares do Colégio das Artes. E a 9 de Fevereiro podia já informar Sebastião José de Carvalho e Melo que tinha ouvido, para o efeito, o lente António Denis de Araújo, considerado como «bastantemente instruido» em matérias que não lhe pertenciam, quanto o era nas da sua área de docência (Cânones). O mestre coimbrão afirmava continuadamente, como lembrou o reitor, não duvidar que era muito necessário um novo método de ensino nas escolas menores e não se eximiu, na oportunidade, a expor sobre ele o seu pensamento $\left(^{(}\right)$.

Depois de aludir em breve notícia à origem e desenvolvimento das referidas escolas, encarecendo a orientação pedagógica que nelas era observada antes de terem sido confiadas aos

* Faculdade de Letras do Porto.

( ${ }^{2}$ Biblioteca Pública Municipal do Porto [ = BPMP], manuscrito 769. A carta do reitor Gaspar de Saldanha de Albuquerque tem, no alto, esta nota de outra mão: He o original.

Este e outros documentos reunidos no mesmo códice foram coligidos por Sílvio Mondânio (pseudónimo do magistrado Manuel Francisco da Silva e Veiga Magro de Moura), que lhes antepôs algumas notas com certo interesse, qualquer delas insuflada pela ideia nova do seu autor. Deixamos algumas notícias sobre ele e a mentalidade contemporânea no artigo A Reforma Pombalina do Ensino das Humanidades (no «Studium Generale», vol. 3. ${ }^{\circ}$, Porto, 1957). 
jesuítas, António Denis de Araújo passou a indicar o que se lhe afigurava como razoável, pelo que dizia respeito à reforma dos estudos de Filosofia e Latim, e a propor que fossem mantidas as cadeiras das línguas Grega, Hebraica, Francesa e Italiana, sem esquecer, obviamente, as destinadas ao ensino da Doutrina Cristã e de ler, escrever e contar. Insistindo, reafirma em outro ponto do seu parecer que a «Gramática Latina é a base para todas as sciências». No alvará da reforma do ensino das Humanidades (28 de Junho de 1759) salienta-se que é "o estudo das Letras Humanas a base de toda a ciência». Mais do que simples coincidência ou influência, poder-se-á admitir que navia, sim, um só espírito e um mesmo objectıvo a atingir, da parte de qualquer iluminista. Não cabe aqui longa explanação sobre o que fica observado e também nos dispensa de tal a circunstância de ser um aspecto por demais sublinhar do e comentado.

Os chamados Estudos Menores, quando iam decorridos treze anos, voltam de novo a ser objecto de diálogo, em ordem a reformá-los.

Foi a Mesa da Comissão Geral do Exame e Censura dos Livros que chamou a si tal encargo, na reunião de 3 de Agosto de 1772, depois de haver concluido que se mantinha e era "fatal o estrago neles causado pela negligência e educação positivamente má dos Jesuítas». Com base no pressuposto, concluiu ainda que era da sua obrigação impreterível promover conferências sobre a forma como devia ser restabelecida "uma tão importante e considerável parte da Literatura» $\left({ }^{2}\right)$. No Juizo dos vogais da Mesa, impunha-se, para além do mais, a «instituição de um professor com aula de ensinar a ler caracteres antigos cuja notícia é necessária quotidianamente para muitos e diferentes usos».

Anteriormente, o Compêndio Histórico do Estado da Universidade de Coimbra anotava já e ao que se alegava para dar termo a abusos verificados em diversas áreas do ensino, que cabia à História Literária dar a conhecer "os Códices Manuscritos, os diplomas, os Numismas e as Inscrições" pelo que era necessário descobrir «nos Arquivos preciosos Manuscritos da Antiguidade, que contribuem muito para o aumento das Ciências». Por outro lado, não deixava de condenar a total negligência com que os jesuítas haviam procedido a respeito do es-

$\left({ }^{2}\right)$ Pedro de Azevedo, Linhas Gerais da História da Diplomática em Portugal (em «O Instituto», vol. $74 .^{\circ}$, Coimbra, 1927), remetendo para o arquivo da Mesa da Comissão Geral do Exame e Censura dos Livros, códice 362, fls. 109 v. 
tudo, entre outras matérias, da Hermenêutica, da Cronologia, da Diplomática, da Esfragística, da Numismática e da Lapidária ( ${ }^{8}$ ).

Os votos da Real Mesa Censória, comedidos no plano enunciado, bem como os reparos do Compêndio Histórico, denunciam, mais do que um desejo, uma certeza: era reconhecida a necessidade do recurso às fontes e aproveitar a sua lição. Para que resultasse útil e incontroversa a sua utilização, impunha-se o ensino de disciplinas do âmbito de certas especialidades, as mesmas que ainda hoje e da parte de alguns autores são classificadas como simples Ciências Auxiliares. Tão necessário e urgente se considerava o seu ensino, que os Estatutos da Universidade de Coimbra impunham ou recomendavam, antes de ele ser estabelecido oficialmente, que deviam ser examinados e verificados «os factos históricos com as devidas luzes da Crítica e da Diplomática: averiguando se as ditas fontes, e monumentos, são verdadeiros ou apócrifos». As disposições estatutárias determinavam mais que o Lente de Direito Pátrio, depois do exame de obras de autores nacionais e estran. geiros (prontuários, elucidários, vocabulários antigos e mer dernos, etc.) e quando não contente com a lição deles devia procurar e consultar diplomas, não só os publicados em algur mas colecções como aqueles que existiam, ocultos, nos arquivos públicos e nos cartórios das corporações religiosas. Ser-lhe-ia permitida, para o efeito, a entrada em todos eles, com a faculdade de poder ler e copiar os diplomas que julgasse necessários para a indagação das origens e ilustração das Leis Pátrias $\left({ }^{4}\right)$.

(') Compêndio Histórico do Estado da Universidade de Coimbra no Tempo da Invasão dos nenominados Jesuítas... Lisboa, 1771. Nova edição: Coimbra, 1972.

Recordemos que o Compêndio verbera a História Literária, subentendida como ciência e enquanto empenhada em dar a conhecer, embora sem mais alcançar do que a confusão. Por outro lado, define-lhe, para além de outras, a missão de manifestar quais «os códices manuscritos que contribuem muito para o augmento das Sciencias». Atribuiu-se a autoria do Compêndio a Fr. Manuel do Cenáculo. Aceita-se geralmente, pelo menos, que ele redigiu boa parte do texto ou dos seus tópicos fundamentais, como lembra o Prof. J. Veríssimo Serrão (História de Portugal, vol. VI, Lisboa, 1982, p. 266).

(4) «Persuadirá aos ouvintes, que unão sempre o estudo das Leis Pátrias com a lição da História Civil, e das antiguidades da Nação Portugueza» - estabelecia o Estatuto da Universidade, no Liv. II, Tit. VI, Cap. III.

Comentário de João Pedro Ribeiro: «Esta recomendação, que se fazia quase no fim do Século XVIII, ao Lente de Direito Pátrio, tanto a reputo então inexequível, quanto actualmente, (passado mais de meio 
E certo que esta preocupação do recurso às fontes começou a evidenciar-se no princípio do séc. XVIII e na continuação ou retomar de tentativas anteriores, o que leva a admitir que então o não foi ou podia ser sob a directa influência que veio a exercer o De Re Diplomatica de Mabillon (1681). Citemos, como exemplo e prova, os estudos inéditos do cónego regrante de Santa Cruz de Coimbra, D. José de Cristo (ou de Bretiandos), redigidos na primeira metade do séc. XVII $\left({ }^{5}\right)$.

Porém, essa influência é já detectada nos estudos elaborados por alguns membros da Academia Real da História Portuguesa (fundada em 1720), posto que nem todos os que dela receberam ensinamentos viessem a referir-se, pelo menos, ao autor da obra que os sistematizou...

2. Não é conhecida, repetimos, providência alguma de natureza oficial, proposta e muito menos promulgada, sobre a ensino da matéria das Ciências Auxiliares, anterior ao que foi sugerido pela Real Mesa Censória, a 3 de Agosto de 1772, quando se pronunciou sobre a reforma dos Estudos Menores. E não mais foi então proposto do que a criação de um lugar de professor "com aula de ensinar a ler caracteres antigos". Todavia, três anos antes, havia sido publicado o Plano dos Estudos para a Congregação dos Religiosos da Ordem Terceira, no qual o seu autor, Frei Manuel do Cenáculo, incluiu uma Ordenacão assim concebida:

«Também se formarão umas pequenas Colecções, e simplicíssimas, das Regras principais da Crítica, da Arte Diplomática, dos mais Princípios gerais, certos, e seguros, para deles se fazer uso nas Aulas. Ensinará o Mestre a fazer a aplicação

Século, e em que tem assás trabalhado sobre o assumpto,) a considero summamente ardua [...] Mas elle não podia ter cem braços. $\mathrm{E}$ indisputável que um edifício magestoso e solido depende, até para os seus alicerces, que trabalhem primeiro os Cabouqueiros na pedreira. $\mathrm{E}$ o que sabiamente meditou a Academia Real das Sciencias de Lisboa, promovendo o exame dos Cartorios: não menos lembrou ao Governo a creação de uma Cadeira de Diplomática, que habilitava Collaboradores desta empreza» (Reflexões Históricas, Parte I, n. ${ }^{\circ} 1$ e 2, Coimbra, Imprensa da Universidade, 1835).

João Pedro Ribeiro, já retirado da docência por força da idade e dos achaques continuados, não emitiu, na oportunidade, opinião favorável quanto aos resultados obtidos através da reforma pombalina do Ensino. Não deixa de aludir, todavia, e com palavras de apreço, nas suas Reflexões Históricas, às determinações de Pombal sobre os cartórios seculares e eclesiásticos da fndia, mandando-os recolher, no todo ou em parte, à Torre do Tombo.

(5) BPMP., códices 84, 86 e 89. Sobre D. José de Cristo e os seus estudos, v. António Cruz, Santa Cruz de Coimbra na Cultura Portuguesa da Idade Média, vol. I, Porto, 1964. 
prática dos mesmos Princípios, e Regras fundamentais, confrontando-os com a Matéria para facilitar a reflexão, e segurança de deduzir consequências destas» $\left(^{8}\right)$.

Ao falar-se de Arte Diplomática, recordemos que, ao tempo, a Paleografia andava incluída no conceito e objecto daquela área. Só mais tarde vem a conquistar plena autonomia e a libertar-se de tal domínio, tendo sido o beneditino francês D. Bernardo de Montfaucon quem primeiro empregou o termo Paleografia (1708) na acepção em que ele passou a ser usado nos meados de Setecentos para designar a nova Ciência $\left(^{7}\right)$.

O Plano dos Estudos de autoria de Frei Manuel do Cenáculo mereceu aprovação régia a 3 de Junho de 1769. Decorridos quatro anos e também por sua iniciativa (1773), saia dos prelos da Impressão Régia um pequeno volume ou manual com a reedição do texto original da parte oitava do Nouveau Traité dos mauristas Toustain e Tassin, declaradamente destinado a facilitar o ensino da Diplomática $\left({ }^{8}\right)$.

Por esse tempo, um cónego regrante, D. Bernardo da Encarnação, dedicava-se a estudos sobre temas da área da Diplomática, revelando um invulgar conhecimento paleográfico de toda a vez que transcrevia diplomas medievais, bem comprovado nas Memórias que escreveu durante o período em que exercitou o cargo de cartorário do mosteiro da Serra do Pilar (1749-1770) e que continuam inéditas. Mais tarde, ao conhecer e identificar esses manuscritos, João Pedro Ribeiro viria a classificar o seu autor como "incansável e sábio religioso" $\left({ }^{\circ}\right)$.

Também na Congregação de São Bento, ainda na primeira metade do séc. XVIII, alguns monges revelaram uma proveitosa aplicação ao estudo da Diplomática e à prática paleográfica. Um deles, Fr. João Crisóstomo de Santo Tomás (professou em 1742), chegou a escrever um manual intitulado $\mathrm{Pa}$ leografia ou Methodo de ler as letras antigas, com abecedários próprios - manuscrito que Fr. Francisco de São Luís, podemos admiti-lo, conheceu e inventariou na livraria do Mosteiro

(') Fr. Manuel do Cenáculo, Plano dos Estudos para a Congregação dos Religiosos da Ordem Terceira de S. Francisco do Reino de Portugal. Lisboa, 1769.

(') Bernardo de Montfaucon, Palaeographia graeca sive de ortu et progressu literarum. Paris, 1708.

(') Méthode de Diplomatique, texto extraído da obra Nouveau Traité de Diplomatique, de Dom Toustain e Dom Tassin, impressa em Paris (1750-1756). O Méthode foi dado à estampa na Imprensa Régia, Lisboa, 1773.

(') Sobre D. Bernardo da Encarnação, natural de Aveiro, e a sua obra, pode ver-se o que escrevemos em Observaçōes sobre o Estudo da Paleografia em Portugal, Porto, 1968. 


\section{O Marquês de Pombal}

de Tibães e veio a extraviar-se posteriormente $\left({ }^{10}\right)$. Outro monge, Frei António da Soledade, revelou-se como perito em Diplomática - di-lo um seu biógrafo - pelos meados do séc. XVIII, tendo comprovado os seus conhecimentos na ordenação que deu a vários cartórios da sua Congregação ( ${ }^{11}$ ). Para não citar mais religiosos que vieram a dedicar-se, alguns com invulgar proveito, ao estudo das Ciências Auxiliares, porém já no período posterior às primeiras diligências empreendidas com o propósito de obter, pelo mínimo, a oficialização do ensino da Paleografia.

3. Ainda no período anterior a tais diligências, é fácil detectar, em um ou outro instituto ou congregação religiosa, alguma preocupação de reforma, na vida interior ou na projecção para além do claustro. Talvez mais por influência recebida do mesmo exterior, quase sempre, embora não faltasse, no seio de cada uma dessas corporações, quem sentisse o efeito directo das «luzes». Todavia, a preocupação só veio a conduzir a resultado útil depois de ter sido ordenada a elaboração ou adaptação de planos de estudos de acordo com o que foi estabelecido superiormente. E oportuno lembrar, a propósito, o que foi posto em causa - muitos anos depois: em 1814! por um livro polémico.

O autor da obra Os Frades julgados no Tribunal da Ra$z a \tilde{o}\left({ }^{12}\right)$, depois de afirmar que foram os regulares os primeiros a ensinar publicamente em Coimbra a filosofia moderna, citando os nomes de quem o fez nos crúzios, nos beneditinos $\epsilon$ nos gracianos, adianta que o mesmo método foi o seguido pelos continuadores desses mestres, para vir a concluir que a reforma da Universidade só veio a verificar-se quinze anos depois de as escolas monásticas se terem reformado a si mesmas. A afirmação não corrresponde inteiramente à realidade,

$\left({ }^{10}\right)$ António Cruz, Observações cit. p. 35. A referência ao $\mathrm{Ma-}$ nual de Fr. João Crisóstomo de Santo Tomás, que se extraviou, colhe-se no códice 395 da BPMP., que contém um catálogo da livraria de Tibães, casa-mãe da Congregação Beneditina, relativo aos seus manuscritos e obras raras, admitindo-se que o tenha preparado Fr. Francisco de São Luis Saraiva.

(11) António Cruz, Observaçōes, p. 31 e segs.

(12) O autor de Os Frades julgados no Tribunal da Razão, figurando no rosto do volume sob disfarce, [Fr. *** Doutor Conimbricense] não foi ainda identificado sem lugar a dúvida. Do texto e respectivas notas, quando apreciados no seu todo ou pormenor, ressalta a possibilidade de admitir que tenha sido mais do que um a concebê-lo e a notá-lo, confiada, embora, a um só a redacção final. Uma das notas atribuidas ao Editor dá o texto como escrito em 1791, porém do mesmo texto se colhe que o foi muito depois. 
dado que as reformas das escolas em causa se processaram em obediência a Planos de Estudos propositadamente elaborados para o efeito e para cada uma das congregações ou provincias e as datas da publicação de quase todos esses Planos é posterior a 1772 .

$\mathrm{Na}$ verdade, a reforma da Universidade é iniciada com a entrega dos seus novos Estatutos, em acto solene que decorreu a 3 de Setembro de 1772, aquando da visita do Marquês de Pombal a Coimbra. Ora as datas da publicação dos Planos são as seguintes: 1769 (Ordem Terceira de S. Francisco de Portugal e Religiosos Observantes de S. Francisco da Província do Algarve); 1775 (Religiosos de S. Paulo Primeiro Eremita); 1776 (Religiosos Trinitários, Monges de S. Jerónimo, Religiosos Menores da Província da Piedade, Religosos Menores Reformados da Província da Soledade, Congregação de S. Bento, e Província de Portugal dos Menores Observantes de S. Francisco). A Congregação de S. Bento faria imprimir mais tarde (1789) um Plano e Regulamento dos Estudos, para assim adaptar preceitos regulamentares às exigências do tempo e satisfazendo sem demora o que havia sido deliberado pelos seus superiores.

Há no título do Plano dos Menores Observantes de S. Francisco uma explicação que aponta para a origem de todos os similares: foram preparados com o fim de estabelecer a forma como deviam ser observadas, em cada congregação ou província, as «disposições dos estatutos da Universidade de Coimbra». Apura-se desta maneira que só tinham sido impressos anteriormente à entrega dos mesmos Estatutos os planos de estudos da Ordem Terceira de S. Francisco do Reino de Portugal e dos Religiosos Observantes de S. Francisco da Província dos Algarves. Lembremos de novo que esses foram da iniciativa e redacção de Frei Manuel do Cenáculo, tendo sido aprovados pela provisão régia de 3 de Junho de 1769. Temos então de admitir, por um lado, não ser verdadeira a afirmação feita pelo Autor de Os Frades julgados no Tribunal da Razão. Por outro lado, concluir que a excepção conhecida aponta já para a boa audiência e aprovação que mereceu, da parte de Pombal, o proposto por Frei Manuel do Cenáculo através de um Plano de reorganização de estudos que é anterior à Reforma da própria Universidade.

De resto, como de há muito se aceita, Cenáculo deve ser considerado o cérebro da Reforma, uma vez que nela colaborou de maneira intensa e extensa e "com certa consciência de missão»- como observa o Prof. Francisco da Gama Caei- 
ro $\left.{ }^{18}\right)$. E os princípios que estabeleceu ao reformar os estudos nas casas da Ordem Terceira vieram a exercer influência, talvez decisiva, em reformas posteriores e nas disposições dos próprios Estatutos da Universidade.

Cenáculo, humanista e pedagogo a um tempo, viveu, como raros do seu tempo, a preocupação de divulgar conhecimento e de rasgar novos caminhos à investigação - como hoje é bem sabido e reconhecido. Logo na Parenética, ele denuncia a formação científica e literária de que era dotado e bem o comprovam as suas Memórias Históricas do Ministério do Púlpito (1776). Ao escrever os Cuidados Literários (1791), tem em mira a formação dos jovens e procura encaminhá-los para uma "larga visão dos factos culturais» - como de costume é apontado. Ainda humanista e de espírito bem desperto, afirma-se como crítico, de maneira particular quando promove e orienta estudos das áreas das ciências auxiliares da História, nomeadamente a Paleografia e a Numismática, ou ele próprio se dá a cultivá-las. Mereceu-lhe então particular carinho a Arqueologia. E no seu ideário iluminista, nem sequer andaram esquecidas as bibliotecas: a partir do culto do livro, com a sua adequada defesa e divulgação, ficou-se a dever-lhe o núcleo fundamental das bibliotecas Nacional de Lisboa, de Evora e da Academia das Ciências.

Foi este, sem dúvida, o alto espírito que encaminhou toda a Mesa da Comissão Geral dos exames e censura dos livros (era assim designada ao tempo, repetimos, na correspondência oficial), para o bom entendimento do que se passava em todas as "nações iluminadas da Europa» que tinham feito "vantajosos progressos no estudo diplomático». E a Mesa então delibera (24 de Julho de 1775) submeter à apreciação régia o assunto que entendia digno de providência: "o estabelecimento de uma Cadeira de Diplomática, servida por um mestre hábil com suficiente número de discípulos, que aprendam esta disciplina para interpretarem os copiosos monumentos de que abunda este reino sepultados nos cartórios das catedrais e comunidades, colegiadas e regulares, praticando-se esta cadeira pelas instruções e debaixo da inspecção desta Mesa, observando os desempenhos do mestre e os progressos dos discípulos".

A Mesa prossegue a sua proposta com a indicação da pessoa que julgava mais apta para a docência da Cadeira de Diplomática. Ao gosto e no estilo da época, os membros da Mesa dão-se pressa em adiantar que os moviam e conduziam neste

(13) Francisco da Gama Caeiro, Frei Manuel do Cenáculo. Aspectos da sua Actuação Filosófica. Lisboa, 1959. 


\section{Ciências Auxiliares da História}

passo as "felicíssimas experiências» que o monarca havia feito já "praticar em tudo quanto era relativo ao bem e crédito nacional", encarecendo assim as reformas empreendidas pelo primeiro Ministro.

Na sequência da proposta, a Mesa declara constar-lhe que "o sujeito mais proporcionado para estes fins", pelos exames $\epsilon$ provas que havia dado da sua habilidade, era José Pereira da Silva: ele podia concorrer para a verificação das boas consequências pretendidas, uma vez a cumprir um horário de trabalho que compreendia lições diárias, de manhã e à tarde, bem como a obrigação de ler, no cartório e na biblioteca da Mesa, o que lhe fosse ordenado, vencendo 400.000 reis cada ano.

Sebastião José de Carvalho e Melo exara na proposta, a 5 de Agosto de 1775, a informação costumada: Sua Magestade como parece. Quatro dias depois, D. José mandava lavrar uma carta assinada pelo presidente da Real Mesa Censória e passada pela Chancelaria régia, fazendo mercê do lugar de professor de ortografia diplomática, na cidade de Lisboa, a José Pereira da Silva, tendo em consideração as letras, qualidades e merecimentos que nele concorriam. A todos os ministros, oficiais e mais pessoas era ordenado que deixassem o mesmo professor gozar de todas as honras, privilégios, liberdades $\mathrm{e}$ isenções que lhe eram concedidas, sob condição de rigorosa observância das instruções determinadas para as escolas menores. $\mathbf{E}$ assim foi oficializado, a 9 de Agosto de 1775, o ensino da Paleografia em Portugal.

Não pode ser ignorado que a criação da Cadeira de Diplomática (designacão que lhe deu, na sua proposta, a Real Mesa Censória) ou de Ortografia Diplomática, como diz a carta de nomeação do seu primeiro professor, foi antecedida por um movimento que integrou meros curiosos ou corporações e ficou assinalado pelo empenho posto na busca, interpretação e aproveitamento de fontes. Aludimos já a um ou outro caso do domínio da Diplomática, campo vasto onde bem cedo, porque anteriormente à divulgação da obra de Mabillon e seus continuadores, deram boa prova da sua capacidade alguns membros do clero regular. E não pode ser esquecida, embora passivel de crítica, a obra meritória, quer nesse, quer em outros campos adjacentes, com uma programada e ensaiada cobertura de todo o domínio das Ciências Auxiliares.

Pertenceu também à nossa primeira Academia de fundação régia o futuro ministro de $\mathrm{D}$. José e Marquês de Pombal. Todavia, não lhe coube, nem a muitos dos seus consócios, revolver cartórios, para aí copiar ou extractar documentos des- 


\section{O Marquês de Pombal}

tinados às obras que projectaram ou escreveram. 0 título de académico, para muitos, era mais honraria do que sinal de compromisso assumido.

Escreveu-se já que não foi verificado o mínimo progresso nos estudos da Diplomática durante o reinado de D. José, embora com a ressalva de terem sido meritórios os esforços dispendidos nos seus últimos anos. A idade de ouro da Diplomática - acrescenta-se - apenas teria coincidido com o reinado de D. Maria I. A afirmação suscita, pelo menos, alguns reparos $\left({ }^{14}\right)$.

Ao pretender-se fundamentar no número e qualidade dos que se deram ao estudo da Diplomática a sua idade de ouro, certo é que leva grande vantagem sobre os anteriores ou imediatamente posteriores, numa avaliação quantitativa e qualitativa, o período coincidente com a charneira os sécs. XVIII-XIX. Não pode ser ignorado, todavia, que muitos outros pesquisadores ou intérpretes das fontes da nossa História, muito antes do início do governo de D. Maria I (1777), haviam já ligado o seu nome a trabalhos de mérito. Por outro lado, se é certo que a Cadeira de Diplomática foi de novo criada e incorporada na Universidade por Carta de 6 de Janeiro de 1796 (assinada pelo Príncipe D. João) e para ela então nomeado como seu Mestre o grande diplomatista Doutor João Pedro Ribeiro, também não é menos certo que a primeira criação da Cadeira se ficou a dever a D. José, com parecer favorável de Sebastião José de Carvalho e Melo e sob inspiração e proposta de Fr. Manuel do Cenáculo.

Em 1796, era chamado à regência da Cadeira, pelos «talentos, inteligência, zelo e préstimo» demonstrados nos seus

(14) Pedro de Azevedo, Linhas Gerais, cit., p. 14. Mais que os estudos, meramente científicos, da Academia Real da História, a que ele pertencia, Pombal - na opinião de Pedro de Azevedo - apreciaria sobretudo os escolares, pelo seu temperamento realista e prático. Não parece ser esta, embora invocada com esse fim, razão bastante para concluir que durante o seu governo não se observou o «mínimo progresso nos estudos diplomáticos». O que procuramos expor, sucintamente, desta vez, leva a conclusão diversa.

No particular do domínio de outras Ciências Auxiliares, não deve esquecer-se a decisão de Pombal, em 1757, ao mandar imprimir exemplares do novo Inquérito concebido pelo padre Luís Cardoso para reconstituir o seu anterior arquivo, em parte destruido pelo terramoto, e assim preparar a Descrição das freguesias do Reino que havia projectado. Concretamente, muito se pretendia saber, inclusive notícias pormenorizadas também do âmbito da Arqueologia, da Etnografia, etc.: a comprová-lo, aí estão, publicados no Arqueólogo Portuguez, os extractos das respostas coligidos por Pedro de Azevedo (vol. I, Lisboa, 1895). 
trabalhos, o Doutor João Pedro Ribeiro, com o vencimento de 400.000 reis em cada ano que lhe passou a ser pago a partir da data da sua nomeação, porém dispensado do "imediato exercício da Cadeira» para continuar por algum tempo as «suas indagações e trabalhos, extraordinariamente adiantados", a fim de sobre eles tornar mais completo o seu "plano de ensinar». Nomeado para o ensino da Diplomática em 1775, José Pereira da Silva vencia também 400.000 reis em cada ano, embora não graduado ou integrado no corpo docente da Universidade. Só a 15 de Maio de 1777 é que a carta da sua nomeação foi registada na Chancelaria. Certamente o foi quando ele já não regia ou não tinha, sequer, iniciado a regência da cadeira: dela o teria impedido a morte. Subsistiu, presume-se, a intenção que havia determinado a oficialização do ensino da Diplomática - e logo o da Paleografia - e a nomeação do seu mestre: é o que se apura de uma referência de Trigoso Morato inserida no seu elogio de Fr. Manuel do Cenáculo e segundo a qual, anos após o falecimento do primeiro Mestre, a cadeira era ainda considerada como fixa e permanente, segundo o disposto nas Instituições para as Aulas, colhendo-se indicação idêntica em José Silvestre Ribeiro $\left({ }^{15}\right)$.

A partir de confronto de datas e à luz do que tem sido apurado até hoje, não é ousado admitir que Portugal foi um dos pioneiros na oficialização do ensino da Diplomática e $\mathrm{Pa}$ leografia. De fundação anterior à primeira Cadeira, em 1775, terá sido a de Bolonha, criada em 1765. Mais tarde, em 1819, ensaia-se e incrementa-se na Alemanha a orientação científica do mesmo estudo, através da Societas Aperiendis Fontibus Rerum Germanicorum - porém ao tempo e desde 1796 funcionava de novo em Portugal a Cadeira de Diplomática, dessa vez a cargo de um docente universitário, o Doutor João Pedro Ribeiro. Ela era a "unica em toda a Hespanha» e assim o declarava o seu Mestre. Na França, só em 1821 é que foi criada a famosa Ecole des Chartes.

Para concluir: integra-se no conjunto de decisões relacionadas com a reforma pombalina dos Estudos (Menores e Superiores) a oficialização, pela primeira vez, da docência da Ca-

${ }^{\left({ }^{15}\right)}$ Francisco Manuel Trigoso de Aragão Morato, Elogio Histórico de [...] D. Fr. Manuel do Cenáculo, nas «História e Memórias da Academia Real das Sciencias de Lisboa», T. IV, Lisboa, 1815, José Silvestre Ribeiro, História dos Estabelecimentos Científicos, Literários e Artísticos de Portugal, Lisboa, 1871-1914. 
deira de Diplomática. Só um forte motivo, imprevisível e insuperável, retardou ou impediu a regência. Mas prevaleceu o espírito e o propósito que determinaram a oficialização. 